\title{
Effectiveness of a heat and moisture exchanger in preventing hyperpnoea induced bronchoconstriction in subjects with asthma
}

\author{
THOMAS R GRAVELYN, MARK CAPPER, WILLIAM L ESCHENBACHER \\ From the Division of Pulmonary and Critical Care Medicine, Department of Internal Medicine, University of \\ Michigan Medical Center, Ann Arbor, Michigan, USA
}

\begin{abstract}
The effect of a heat and moisture exchanger, a device with hygroscopic material for conditioning inspired air, on hyperpnoea induced bronchoconstriction was studied in nine nonsmoking volunteers with asthma, aged 19-32 years. Each had previously shown an increase of at least $100 \%$ in specific airways resistance (sRaw) to isocapnic hyperpnoea with dry air. On two separate days the subject performed isocapnic hyperpnoea with dry air at $60-701 \mathrm{~min}^{-1}$ for five minutes. Before, immediately after, and five minutes after completion of a test sRaw measurements were made. Heat and moisture exchangers were placed in the breathing circuit on one of the two days. All subjects had an increase in sRaw of $100 \%$ or more without the heat and moisture exchangers (average increase $300 \%$ ) but were protected from bronchoconstriction with the devices in place (average increase $7 \%)(p<0.005)$. The exchanger's resistance to airflow was less than $1 \mathrm{~cm} \mathrm{H}_{2} \mathrm{O}$ for flow rates of $1001 \mathrm{~min}^{-1}$. A heat and moisture exchanger designed as a facemask or mouthpiece may allow a person with asthma to exercise without the need for prophylactic drugs.
\end{abstract}

\section{Introduction}

The stimulus for exercise induced bronchoconstriction is unknown, although many investigators believe that respiratory heat and water loss are important contributing factors. ${ }^{1-7}$ Earlier studies have shown that conditioning the inspired air to minimise heat and water loss during exercise in subjects with asthma can prevent the development of bronchoconstriction. ${ }^{89}$

Heat and moisture exchangers are simple devices containing hygroscopic material that absorbs water from exhaled air and transfers the moisture to dry inhaled air. ${ }^{10-12}$ They have a low resistance to airflow, require no external power source and no water supply, and function efficiently whatever the individual's tidal volume.

We suggested that the use of a heat and moisture exchanger by individuals with asthma would warm and humidify dry inspired air and reduce the stimulus

Address for reprint requests: Dr William L Eschenbacher, University of Michigan Medical Center, Room B1H272, Box 0026, 1500 E Medical Center Drive, Ann Arbor, Michigan 48109-0026, USA.

Accepted 15 June 1987 to bronchoconstriction (water or heat loss, or both) with exercise or isocapnic hyperpnoea. As isocapnic hyperpnoea elicits airway responses similar to those of exercise, ${ }^{41314}$ we studied the effectiveness of a heat and moisture exchanger in preventing isocapnic hyperpnoea induced bronchoconstriction in subjects with asthma.

\section{Methods}

We studied nine non-smoking volunteers with asthma (table)-six women and three men aged 19-32 years. The diagnosis of asthma was made by a history of recurrent episodes of wheezing, chest tightness, and reversible airways obstruction previously documented by a physician. Each subject showed a greater than $100 \%$ increase in specific airways resistance (sRaw) to an inhalation challenge of doubling concentrations of methacholine at a concentration of less than $1 \mathrm{mg} / \mathrm{ml}$, and had previously shown a greater than $100 \%$ increase in sRaw to isocapnic hyperpnoea with dry air. Four of the subjects required daily medication for their asthma but all treatment was withheld for 24 hours before any experiment. Each subject signed a consent form approved by the Human Use Committee of the University of Michigan. 
Characteristics of the subjects

\begin{tabular}{|c|c|c|c|c|c|c|c|}
\hline Subject No & Sex & Age (y) & Height $(\mathrm{cm})$ & $F E V_{1}(l)$ & $F V C(l)$ & $P D_{100} M(\mathrm{mg} / \mathrm{ml})$ & Medication \\
\hline $\begin{array}{l}1 \\
2 \\
3 \\
4 \\
5 \\
6 \\
7 \\
8 \\
9\end{array}$ & $\begin{array}{l}\mathbf{F} \\
\mathbf{M} \\
\mathbf{M} \\
\mathbf{F} \\
\mathbf{F} \\
\mathbf{F} \\
\mathbf{F} \\
\mathbf{M} \\
\mathbf{F}\end{array}$ & $\begin{array}{l}32 \\
24 \\
23 \\
20 \\
24 \\
19 \\
21 \\
20 \\
23\end{array}$ & $\begin{array}{l}168 \\
180 \\
165 \\
155 \\
168 \\
163 \\
157 \\
178 \\
170\end{array}$ & $\begin{array}{l}2 \cdot 07 \\
3 \cdot 61 \\
3 \cdot 76 \\
2 \cdot 60 \\
3 \cdot 54 \\
2 \cdot 50 \\
3 \cdot 55 \\
4 \cdot 24 \\
3.59\end{array}$ & $\begin{array}{l}3 \cdot 39 \\
4 \cdot 56 \\
4 \cdot 61 \\
3 \cdot 05 \\
4 \cdot 01 \\
3 \cdot 19 \\
4 \cdot 01 \\
5 \cdot 19 \\
4 \cdot 54\end{array}$ & $\begin{array}{l}0.62 \\
0.18 \\
0.18 \\
0.13 \\
0.52 \\
0.13 \\
0.30 \\
0.13 \\
0.20\end{array}$ & $\begin{array}{l}\text { IB, T, IS daily } \\
\text { IB prn } \\
\text { IB prn } \\
\text { IB prn } \\
\text { IB, T prn } \\
\text { IB daily } \\
\text { IB prn } \\
\text { IB, T daily } \\
\text { IB prn }\end{array}$ \\
\hline
\end{tabular}

$\mathrm{PD}_{100} \mathrm{M}$-provocative dose of methacholine required to increase the baseline sRaw by $100 \%$, determined by interpolation from the results $\mathrm{f}$ of a stimulus response challenge with doubling concentrations of methacholine; IB - inhaled bronchodilator; IS-inhaled steroid; T-theophylline preparation; prn-as required.

Subjects were tested on two separate days. For each experiment we first determined airway resistance and thoracic gas volume from five measurements, using a constant volume body plethysmograph (Airco 3000 System, Ohio Medical Products, Houston, Texas) and calculated baseline sRaw (the product of thoracic gas volume and airway resistance, $1 \mathrm{~cm} \mathrm{H}_{2} \mathrm{Ol}^{-1} \mathrm{~s}$ ). The subject then performed isocapnic hyperpnoea for five minutes by inhaling dry air $\left(0 \mathrm{mg} \mathrm{H} \mathrm{H}_{2} \mathrm{O} / 1\right.$ gas) at room temperature $\left(22-24^{\circ} \mathrm{C}\right)$ from a compressed dry air tank through a mouthpiece while wearing a noseclip (fig 1). Expired air was diverted into a reservoir balloon that was continuously evacuated at $701 \mathrm{~min}^{-1}$ through a calibrated rotameter (Fischer and Porter Model 10A 1027A, Warminster, Pennsylvania). The subject was asked to breathe at a rate that would keep the balloon partially inflated at all times, so maintaining the target ventilation of about $701 \mathrm{~min}^{-1}$. The subject's actual expiratory flow rate was determined with a pneumotachograph (Hans Rudolph Model 3800, Kansas City, Missouri) connected to a differential pressure transducer (Validyne Model MP45-5, Northridge, California). The output of the pressure transducer was fed into a carrier demodulator (Hewlett Packard Model 8805B, Palo Alto, California). The flow signal was electronically integrated (Hewlett Packard Model 8815A) and the resulting volume signal was displayed on a paper

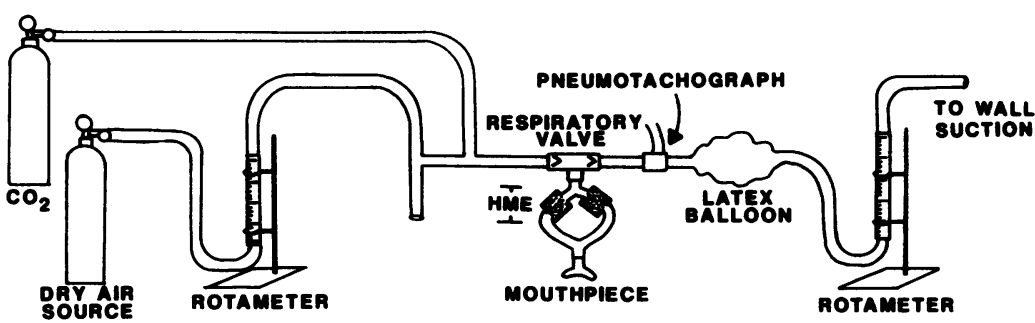

Fig 1 Apparatus used for the isocapnic hyperpnoea challenges. $H M E$ - heat and moisture exchanger. recorder (Gould Brush 2400, Cleveland, Ohio). The paper recorder was calibrated by introducing $\vec{a}$ known volume through the pneumotachograph anc measuring the resulting deflection on the paper recorder. The exhaled minute ventilation values were converted to BTPS conditions. We measured en® tidal carbon dioxide (medical gas analyser LB-2 Beckman, Fullerton, California) and added carbor dioxide to the inlet side of the mouthpiece to keep the patient isocapnic (end tidal carbon dioxide at 4-5\%)o The subject then returned to the body plethys mograph for measurements of sRaw immediately an five minutes after hyperpnoea. On one of the two tes? days two heat and moisture exchangers (ServQ Humidifier 150, Siemens-Elema, Sweden) wer $\overrightarrow{\widehat{E}}$ inserted into the breathing circuit near the mouth 3 piece (fig 1). The Servo Humidifier 150 consists of hygroscopic cellulose sponge and synthetic feli enclosed in a plastic cannister. The two exchangers were connected in parallel to reduce the added resistance. The order of testing was randomised for the nine subjects. The subjects were not told whethe? the use of the heat and moisture exchanger would be expected to help or worsen their response to the hyperpnoea challenge.

Using a separate circuit, we measured the pressure drop across the Servo Humidifier 150 (forward and reverse) at increasing flow rates from one heat anc. moisture exchanger and two exchangers arranged i⿱⺈ parallel using a pressure manometer (Durablock Manometer Model No 42产 Dwyer Instruments, Miche gan City, Illinois). If addition, to determine the change in resistance t@ airflow after the hea and moisture exchangers became moist, the mean pressure drop across the 
breathing circuit as used in the test was determined after five minutes of isocapnic hyperpnoea with dry air in six subjects.

We used a Kruskal-Wallis test for non-parametric analysis with a Tukey type multiple comparison to assess differences between baseline sRaw values and those obtained after dry air hyperpnoea with and without the heat and moisture exchangers in place. The mean ventilatory rates maintained with and without the devices in place were compared with a Student's $t$ test. All values are expressed as means with standard errors in parentheses.

\section{Results}

Without the heat and moisture exchangers in the breathing circuit, the mean sRaw in the nine subjects increased from a baseline value of $6 \cdot 1(0 \cdot 6)$ to $24.4(5.4) \quad 1 \mathrm{~cm} \mathrm{H}_{2} \mathrm{Ol}^{-1} \mathrm{~s}^{*}$ after hyperpnoea, an increase of $300 \%$ (fig 2). With the exchangers in the breathing circuit, the mean increase in sRaw was $7 \%$ $\left(7 \cdot 1(0.9)\right.$ to $\left.7 \cdot 6(1 \cdot 2) 1 \mathrm{~cm} \mathrm{H}_{2} \mathrm{Ol}^{-1} \mathrm{~s}\right)$. The difference in sRaw after hyperpnoea with and without the heat and moisture exchangers in place was significant $(p<$ $0.005)$. There was no significant difference in the mean minute ventilation $(69.0(1.5)$ without the device $v$ $69.6(2.2) 1 \mathrm{~min}^{-1}$ with the device) or in baseline sRaw for the two test days. No subject had cough, chest tightness, or wheezing after isocapnic hyperpnoea

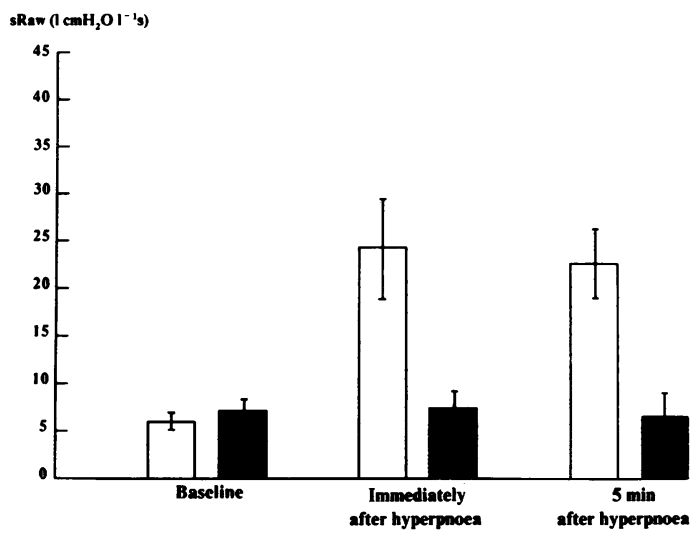

Fig 2 Difference between the specific airways resistance (sRaw) after the hyperpnoea challenge with the heat and moisture exchangers in place ( $\square$ ) and the sRaw after the challenge without the exchangers $(\square)$ (this was significant; $p<0.005)$. The difference was significant for both the immediate posthyperpnoea sRaw and the sRaw five minutes after hyperpnoea. (Factor for converting traditional to SI units $\left(l \mathrm{kPal} \mathrm{l}^{-1} \mathrm{~s}\right)=0 \cdot 1$.)

*The factor for converting traditional sRaw units $\left(1 \mathrm{~cm} \mathrm{H} \mathrm{H}_{2} \mathrm{Ol}^{-1} \mathrm{~s}\right)$ to SI units ( $\left.\mathrm{kPa} \mathrm{I}^{-1} \mathrm{~s}\right)$ is 0.1 . with dry air when the heat and moisture exchangers were in place, but all subjects noted chest tightness and wheezing after isocapnic hyperpnoea with dry air without the devices. They could not discern an increase in resistance to breathing during hypernoea through the exchangers.

The results of the pressure drop measurements are shown in figure 3. When the heat and moisture exchangers were placed in parallel (as was done in the hyperpnoea protocol), the pressure drop across the devices when dry or moist was less than $1 \mathrm{~cm} \mathrm{H}_{2} \mathrm{O}$ even at flow rates of $1001 \mathrm{~min}^{-1}$.

\section{Discussion}

We have shown that water adsorbent or hygroscopic material as found in a heat and moisture exchanger can protect against the development of bronchoconstriction in subjects performing isocapnic hyperpnoea with dry air. Our results support previous studies emphasising respiratory heat and water loss as the primary stimuli in the development of hyperpnoea induced or exercise induced bronchoconstriction. Introducing two heat and moisture exchangers in

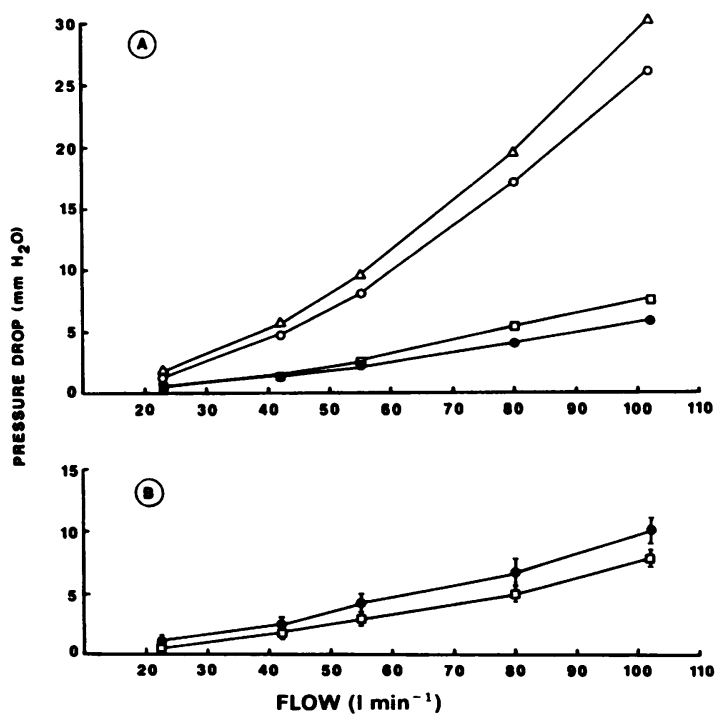

Fig 3 Pressure drop versus flow rate for the breathing circuit with heat and moisture exchangers in place. A-Dry compressed air used with dry heat and moisture exchangers (HMEs): - two HMEs in parallel; inspiration flow direction; $\square$ two HMEs in parallel; expiration flow direction; $\bigcirc$ one $H M E$; inspiration flow direction; $\triangle$ one $H M E$; expiration flow direction. B-Pressure drop across circuit (mean and standard error after five minutes of hyperpnoea with two HMEs in circuit (five trials): $\bullet$ inspiration flow direction; $\square$ expiration flow direction. 
parallel into the breathing circuit resulted in only a small additional resistance to breathing $\left(<1 \mathrm{~cm} \mathrm{H}_{2} \mathrm{O}\right.$ pressure drop at a flow rate of $1001 \mathrm{~min}^{-1}$ ).

Other studies have shown that a simple surgical mask or a respiratory filter ${ }^{1516}$ placed in front of the mouth may partially inhibit exercise induced bronchoconstriction in subjects with asthma. Our approach is different in that we have used materials (a heat and moisture exchanger) that can adsorb moisture and transfer the heat and moisture from exhaled air to inhaled air efficiently and more effectively than the materials used previously. Further work is necessary to determine the most appropriate hygroscopic material, the amount of material necessary for maximal humidification at desired flow rates, and the material with the lowest resistance to airflow.

Prevention of exercise induced asthma with a heat and moisture exchanger could prevent not only the immediate bronchoconstriction at the end of exercise but possibly the late phase response as well. ${ }^{17} 18$ Reducing the frequency or duration (or both) of episodes of bronchoconstriction in people with asthma would decrease the need for prophylactic or symptomatic use of bronchodilators and may also reduce the baseline hyperreactivity of these individuals. For selected sensitive subjects the heat and moisture exchanger would also be a barrier against pollen and soluble air pollutants (such as sulphur dioxide and ozone).

Conditioning the inspired air with a heat and moisture exchanger might also be useful in other disorders, such as cystic fibrosis, chronic bronchitis, and sarcoidosis, that may present with reversible airway obstruction to stimuli such as exercise, cold air, and air polution.

In summary, conditioning the inspired air to minimise heat and moisture loss from the airways associated with isocapnic hyperpnoea can effectively protect against the development of bronchoconstriction in patients with asthma. A heat and moisture exchanger can efficiently provide the necessary heat and moisture output at high ventilatory rates without the addition of appreciable resistance to airflow. A heat and moisture exchanger designed as a mouthpiece or face mask could potentially allow the patient with asthma to exercise without wheezing or the need for prophylactic medication.

\section{References}

1 Eschenbacher WL, Sheppard D. Respiratory heat loss is not the sole stimulus for bronchoconstriction induced by isocapnic hyperpnea with dry air. Am Rev Resp \& Dis 1985;131:894-901.

2 Strauss RH, McFadden ER, Ingram RH, Jaeger JP Enhancement of exercise induced asthma by cold aip N Engl J Med 1977;297:743-7.

3 Strauss RH, McFadden ER, Ingram RH, Deal EC Jaeger JJ. Influence of heat and humidity on the airway obstruction induced by exercise in asthma $J$ Clin Invest 1978;61:433-40.

4 Deal EC, McFadden ER, Ingram RH, Jaeger JJ. Hyper pnea and heat flux: initial reaction sequence in exercise induced asthma. J Appl Physiol 1979;46:476-83.

5 Anderson SD. Is there a unifying hypothesis for exerciseinduced asthma? $J$ Allergy Clin Immunoblo 1984;73:660-5.

6 Hahn A, Anderson SD, Morton AR, Black $\mathrm{JL}_{\odot}$ Fitch KD. A reinterpretation of the effect of temperature and water content of the inspired air in exercise induced asthma. Am Rev Respir Dis 1984;130:575-9.

7 Smith CM, Anderson SD. Hyperosmolarity as the stimu志 lus to asthma induced by hyperventilation. J Allerg, Clin Immunol 1986;77:729-36.

8 McFadden ER, Lerner KAM, Strohl KP. Postexertiona $\overrightarrow{9}$ airway rewarming and thermally induced asthma. Clin Invest 1986;78:18-25.

9 Chen WY, Weiser PC, Chai H. Airway cooling, stimulu@ for exercise induced asthma. Scand $J$ Respir Dis 1979;60:144-50.

10 Anonymous. Heat and moisture exchangers. Emergenc Care Research Institute Health Device 1983;12:155-67.

11 Weeks DB. Humidification during anesthesia. NYS Med 1975;75:1216-8.

12 Gedeon A, Mebius C. The hygroscopic condense humidifier. Anesthesia 1979;34:1043-7.

13 Kilham H, Tooley M, Silverman M. Running, walking and hyperventilation causing asthma in children Thorax 1979;34:582-6.

14 Kivity S, Souhrada JF. Hyperpnea: the common stimug్ lus for bronchospasm in asthma during exercise an voluntary isocapnic hyperpnea. Respiration 1980;40:169-73.

15 Brenner AM, Weiser PC, Krogh LA, Loren MLO Effectiveness of a portable face mask in attenuating exercise-induced asthma. JAMA 1980;244:2196-8.

16 Bengtsson U, Millgvist E, Bake B, Löwhagen $\mathrm{O}=$ Prevention of cold-induced asthma conditioning the inspired air. Eur J Respir Dis 1984;65(suppl 136):45-7?

17 Feldman CH, Fox J, Kraut E, Feldman BR, Davis WJ Exercise induced asthma (EIA): Treatment for earl and late response [abstract]. Am Rev Respir Dis 1982;125:195.

18 Bierman CW. A comparison of late reactions to antigen and exercise. J Allergy Clin Immunol 1984;73:654-9. 